\title{
Predicting ICU length of stay using APACHE-IV in persons with severe sepsis - a pilot study
}

\author{
Amit Chattopadhyay ${ }^{* 1}$, Sharmila Chatterjee ${ }^{2}$ \\ ${ }^{1}$ Case Western Reserve University, Department of Oral Medicine, School of Dental Medicine, Cleveland, OH, USA \\ ${ }^{2}$ University of Nebraska Medical Center, Center for Global Health and Development, College of Public Health, Omaha, NE, USA
}

Received: July 19, 2015

DOI: $10.5430 /$ jer.v2n1p1
Accepted: August 23, 2015

URL: http://dx.doi.org/10.5430/jer.v2n1p1

\begin{abstract}
Introduction: Accurate length of stay (LOS) prediction of severe sepsis patients in intensive care unit (ICU) is critical for resource management. Acute Physiology and Chronic Health Evaluation-IV (APACHE-IV) model is commonly used for predicting LOS. This study assesses the ICU-LOS predictability of APACHE-IV system for severe sepsis patients.

Methods: Following ethical clearance, we used ICU data (06/2006 - 08/2008: from a hospital in India) to compare APACHE-IV score and predicted LOS of severe sepsis patients with actual observed ICU-LOS. We employed $t$-test, correlations, ANOVA and linear regression of suitably transformed variables as needed.

Results: Out of 3,949 ICU admissions, 198 were severe sepsis admissions where 134 patients $(80 \%)$ had usable data. Of these 75 had verifiable APACHE-IV scores (final sample) with 55\% men; median age: 67 years (IQR: 21) 53\% did not have dialysis; 87\% were on mechanical ventilation (MV). Mean ICU-LOS (10.1 days + 6.4) was significantly greater than predicted ICU-LOS (5.6 days $+1.8 ; p<.001)$. ICU-LOS was very strongly correlated with days on MV $(r=0.9)$. Mean ICU-LOS was significantly greater for those receiving blood transfusion $(p<.001)$; on MV $(p<.001)$; having surgery $(p<.001)$ and having high frequency of dialysis $(p<.001)$ - differences not predicted by APACHE-IV. Overall, the predicted ICU-LOS underestimation was by 4.5 days.

Conclusions: The results provide a preliminary indication that APACHE-IV model may be a poor predictor of ICU-LOS in severe sepsis cases.
\end{abstract}

Key Words: Length of stay, Intensive care unit, Acute Physiology and chronic health evaluation, Prediction

\section{INTRODUCTION}

Worldwide, sepsis is an important cause of intensive care unit (ICU) admissions, the leading cause of death in non-coronary ICUs $^{[1,2]}$ and the 10th overall leading cause of death. ${ }^{[3]}$ Despite the availability of potent antibiotics and refined supportive care, mortality of sepsis patients remains high (30\%; and $50 \%$ when shock-associated). Severe sepsis is defined as the presence of infection, a systemic inflammatory response syndrome (SIRS) and acute organ dysfunction. ${ }^{[4]}$ Sepsis complicated by organ dysfunction has a high mortality rate ranging from $28 \%$ to $50 \% .^{[5]}$ Septic shock is severe sepsis with acute circulatory failure characterized by persistent arterial hypotension unexplained by other causes. In 1995, Angus et al. ${ }^{[6]}$ estimated that more than 750,000 cases of severe sepsis occur annually in the United States (U.S.). Yet, the epidemiology of sepsis remains poorly described except in a few reports. ${ }^{[7]}$ In the Indian context, basic epidemiologic and health care questions such as estimates of population,

\footnotetext{
*Correspondence: Amit Chattopadhyay, Adj. Professor; Email: amit.chattopadhyay@case.edu; Address: Case Western Reserve University, Department of Oral Medicine, School of Dental Medicine, Cleveland, OH, USA.
} 
incidence, risk factors for the development and outcomes of severe sepsis have not been addressed by any studies. ${ }^{[8]}$

Prediction of length of stay (LOS) in ICUs is generally conducted using proprietary algorithmic tools. The Acute Physiology and Chronic Health Evaluation (APACHE) system, ${ }^{[9]}$ now in the fourth version, incorporating measures of physiologic derangement and comorbidities, was designed to predict an individual's risk of dying in a hospital by each individual's medical profile against nearly 18,000 cases in its memory. It has been suggested that APACHE-IV predictions of hospital mortality have good discriminative power and should be useful for benchmarking performance in the U.S. ICUs. ${ }^{[10]}$ It has been further suggested that the accuracy of this dynamic predictive model should be retested periodically. ${ }^{[10]}$ It also provides LOS in ICUs based on several physiologic criteria. Specific to predicting ICU-LOS, the developers have suggested that the accuracy and utility of ICU-LOS prediction from the APACHE-IV model, though clinically useful for critically ill patients, apply to individual patients and may not be useful for groups. However, APACHE-IV benchmarks for ICU stay have been used for assessing the efficiency of unit throughput and for supporting examination of structural, managerial, and patient factors impacting LOS. ${ }^{[11]}$ APACHE-IV is used internationally widely as a prediction tool for ICU-LOS and has been suggested to be very valuable for this purpose..$^{[11-13]}$

There are, until now, no studies that have assessed ICU-LOS predictability of APACHE-IV models in severe sepsis where the impacts of patho-physiological misbalances are gravest. Aiming to assess ICU-LOS predictability of APACHE-IV, the overall research question for this study was: does the current LOS prediction tool (APACHE-IV) used in the hospitals accurately predict the LOS of severe sepsis patients admitted to an ICU?

\section{Methods}

This study at AMRI Hospitals, Kolkata, India, approved by the hospital Ethics Committee was nested within the Epidemiology of Severe Sepsis Study. ${ }^{[8]}$

\subsection{Sample}

All consecutive new adult admissions to ICU (no previous admission to ICU) with severe sepsis as per standard criteria $^{[4]}$ between 1st June, 2006 and 31st August, 2008 were eligible. These patients were followed up till they were discharged from ICU. APACHE-IV predicted ICU-LOS was calculated. At close of study, their actual ICU-LOS was calculated. Patients who stayed in the ICU for less than 24 hours for routine post-operative surveillance or those who were discharged alive from ICU within 24 hours without developing sepsis or complications, were excluded.

\subsection{Data collection}

Hospital records and study specific record sheets provided data including demographics, admission category, and clinical attributes. Procedures and surgical events during patients' stay at ICU, attending physician information and clinical test data were included. All diagnoses were validated through careful assessment of clinical notes in the charts. Participants were given a unique study identification number in the deidentified database. All data collected were as per hospital's quality assurance standards for staff training, data collection and record-keeping. All data were double entered into computers for quality assurance and error checks were performed. Discrepancies were resolved by counter-checking with the hard copy of medical records. Data cleaning was done through a programmed range-check on values of data points. All missing values/out of range values were compared with the hard copy/source records to ensure comprehensive and accurate data extraction. If missing values still existed, their distribution was analyzed. Outliers were reduced to mean $+/-3 \mathrm{SD}$ to allow analysis and conserve power. All analysis and graph generation were was carried out using a "clean" data set in IBM SPSS Statistics for Windows, Version 19.0.

\subsection{Statistical analyses}

From a total of 3,949 ICU admissions, 45 duplicate entries were removed leaving an initial pool of 3,904 patients. Of these, 198 remained with a diagnosis of having severe sepsis. Out of these 30 re-admissions were removed. Some data were not available for 34 patients leaving a study sample of 134 individual patients. APACHE-IV data was available for 75 patients; therefore most analysis was restricted to these cases only.

Univariate distribution of variables were computed and noted for their deviations from normalcy, skewness, and kurtosis. LOS and days with mechanical ventilation (MV) exhibited skewed distribution, and were natural-log-transformed to meet Gaussian distribution assumption. To understand if APACHE-IV prediction difference with actual was in the same direction (i.e. if it always under-predicted or over predicted), we assessed the percent difference between actual and APACHE-IV predicted ICU-LOS [(predicted ICU-LOS - actual ICU-LOS)/predicted ICU-LOS] for each case.

Because each patient acted as his/her own "control", predicted ICU-LOS and actual ICU-LOS were deemed correlated and paired analyses were conducted to test the differences between predicted mean ICU-LOS and actual ICULOS. Other sub-group comparisons used unpaired analytical 
paradigm after testing for equality of variances - ICU-LOS differences between groups (sex, age groups, de-identified treating physician, type of admission source, and different procedures during ICU stay) were tested using Pearson's correlation coefficient, independent $t$-Tests and ANOVA with Scheffe's pair-wise test for multiple comparisons as needed. Ordinary linear regression was employed to derive linear trend lines for LOS factors.

\section{Results}

Distributions of important study related factors are presented in Table 1 for those whose APACHE-IV scores were available, as well as for those whose scores were not available.
Some $54.7 \%$ of the sample (with APACHE-IV scores) were men; $35.6 \%$ being women. The overall mean age of the sample was 64.2 years (standard deviation-SD: 15.9), whereas median age was 67 years (Inter quartile range-IQR: 21) and the range was 18 years to 72 years. The range of number of times severe sepsis patients in the ICU underwent dialysis varied between 0 and 17, with most not having had any dialysis $(58.2 \%)$ (see Table 1). Most patients underwent some procedures or surgeries during their stay in the ICUs. Most patients (86.7\%) were put on MV (see Table 1). The overall mean days for which patients were on MV was 7.37 days (SD: 6.3); median was 6 days (IQR: 9) for those on MV.

Table 1. Distribution of important determinant variables for Length of Stay (LOS) in ICUs

\begin{tabular}{|c|c|c|c|c|c|c|c|}
\hline \multirow[t]{2}{*}{ Variable } & \multirow[t]{2}{*}{ Levels } & \multicolumn{2}{|c|}{$\begin{array}{l}\text { APACHE-IV score } \\
\text { available }\end{array}$} & \multicolumn{2}{|c|}{$\begin{array}{l}\text { APACHE-IV score not } \\
\text { available }\end{array}$} & \multicolumn{2}{|l|}{ Total } \\
\hline & & Number & Percent (\%) & Number & Percent (\%) & Number & Percent (\%) \\
\hline \multirow{4}{*}{$\begin{array}{l}\text { Hospital } \\
\text { Outcome }\end{array}$} & Discharged on Risk Bond & 7 & 9.3 & 2 & 3.4 & 9 & 6.7 \\
\hline & Death & 44 & 58.7 & 36 & 61.0 & 80 & 59.7 \\
\hline & Discharged & 23 & 30.7 & 21 & 35.6 & 44 & 32.8 \\
\hline & In Hospital & 1 & 1.3 & 0 & 0.0 & 1 & 0.8 \\
\hline \multirow{2}{*}{$\begin{array}{l}\text { Blood } \\
\text { Transfusion }\end{array}$} & No & 32 & 42.7 & 28 & 47.5 & 60 & 44.8 \\
\hline & Yes & 43 & 57.3 & 31 & 52.5 & 74 & 55.2 \\
\hline \multirow{4}{*}{$\begin{array}{l}\text { Dialysis } \\
\text { (Number of } \\
\text { Times) }\end{array}$} & 0 & 40 & 53.3 & 38 & 64.4 & 78 & 58.2 \\
\hline & 1 & 5 & 6.7 & 6 & 10.2 & 11 & 8.2 \\
\hline & $2-6$ & 20 & 26.7 & 10 & 16.9 & 30 & 22.4 \\
\hline & $>6$ & 10 & 13.3 & 5 & 8.5 & 15 & 11.2 \\
\hline \multirow{2}{*}{$\begin{array}{l}\text { Procedures } \\
\text { in ICU }\end{array}$} & No & 8 & 10.7 & 3 & 5.1 & 11 & 8.2 \\
\hline & Yes & 67 & 89.3 & 56 & 94.9 & 123 & 91.8 \\
\hline \multirow{3}{*}{$\begin{array}{l}\text { Surgery } \\
\text { During ICU } \\
\text { stay }\end{array}$} & No & 67 & 90.5 & 52 & 88.1 & 119 & 89.5 \\
\hline & Yes & 7 & 9.5 & 7 & 11.9 & 14 & 10.5 \\
\hline & Missing information & 1 & -- & -- & -- & 1 & -- \\
\hline Mechanical & No & 10 & 13.3 & 12 & 20.3 & 22 & 16.4 \\
\hline Ventilation & Yes & 65 & 86.7 & 47 & 79.7 & 112 & 83.6 \\
\hline
\end{tabular}

The overall actual mean ICU-LOS for severe sepsis patients was 10.12 days (SD: 6.4); median was 8 days (IQR: 9) and range: 2-29 days. The mean total hospital stay varied somewhat from the mean ICU-LOS, but was not statistically significantly different. The predicted mean ICU-LOS score, was 5.6 days (SD: 5.7); median being 5.7 days (IQR: 2.6); and the range being 2.09 day -8.99 days (see Table 2). The actual LOS was significantly higher than the predicted LOS.

The overall actual mean ICU-LOS was 4.49 days higher Linear regression analysis suggested that a model for predictthan the predicted mean ICU-LOS ( $p<.001)$ (see Table 2). ing actual ICU-LOS with only the constant was the same as 
one with any predictors (see Table 2). Figure 1 shows the the regression line). These results suggest poor correlation scatterplot of actual ICU-LOS and predicted ICU-LOS (with between predicted ICU-LOS and actual ICU-LOS.

Table 2. Mean Length of Stay (LOS) of severe sepsis patients categorized by important variables $(\mathrm{SD}=\mathrm{Standard}$ Deviation). APACHE-IV consistently under-predicts LOS by a large magnitude.

\begin{tabular}{|c|c|c|c|c|c|c|c|}
\hline \multirow[t]{2}{*}{ Study Factor } & \multirow[t]{2}{*}{ Category } & \multirow[t]{2}{*}{ Number } & \multicolumn{2}{|c|}{$\begin{array}{l}\text { Actual ICU } \\
\text { LOS (days) }\end{array}$} & \multicolumn{2}{|c|}{$\begin{array}{l}\text { APACHE-IV } \\
\text { Predicted ICU } \\
\text { LOS (days) } \\
\end{array}$} & \multirow{2}{*}{ Percent Difference } \\
\hline & & & Mean & SD & Mean & SD & \\
\hline ICU-LOS* & Total & 75 & 10.12 & 6.4 & 5.63 & 1.8 & -79.8 \\
\hline \multirow{2}{*}{$\begin{array}{l}\text { Arrival Time in } \\
\text { ICU }\end{array}$} & $\mathrm{AM}$ & 15 & 11.33 & 6.5 & 4.72 & 1.7 & -140.0 \\
\hline & $\mathrm{PM}$ & 58 & 9.91 & 6.5 & 5.77 & 1.7 & -71.8 \\
\hline \multirow{2}{*}{ Sex } & Women & 34 & 9.44 & 6.8 & 5.62 & 1.7 & -68.0 \\
\hline & Men & 41 & 10.68 & 6.1 & 5.64 & 1.9 & -89.4 \\
\hline \multirow{4}{*}{$\begin{array}{l}\text { Hospital } \\
\text { Outcome }\end{array}$} & $\begin{array}{l}\text { Discharged on Risk } \\
\text { Bond }\end{array}$ & 7 & 11.57 & 8.9 & 4.70 & 2.2 & -146.2 \\
\hline & Death & 44 & 10.48 & 6.1 & 5.76 & 1.8 & -81.9 \\
\hline & Discharged & 23 & 8.96 & 6.4 & 5.69 & 1.8 & -57.5 \\
\hline & In Hospital & 1 & 11.00 & -- & 5.1 & -- & -115.7 \\
\hline \multirow{2}{*}{$\begin{array}{l}\text { Blood } \\
\text { Transfusion }\end{array}$} & No & 32 & $7.81^{*}$ & 5.4 & 5.94 & 1.8 & -31.5 \\
\hline & Yes & 43 & $11.84^{*}$ & 6.6 & 5.40 & 1.8 & -119.3 \\
\hline \multirow{4}{*}{$\begin{array}{l}\text { Admission } \\
\text { Source: } \\
\text { Department }\end{array}$} & Emergency Dept. & 11 & 13.00 & 6.3 & 5.10 & 1.6 & -154.9 \\
\hline & Medicine Dept. & 37 & 8.92 & 6.2 & 5.50 & 1.9 & -62.2 \\
\hline & Surgery Dept. & 10 & 12.30 & 6.9 & 6.55 & 2.1 & -87.8 \\
\hline & Other Departments & 16 & 9.44 & 6.4 & 5.74 & 1.5 & -64.5 \\
\hline \multirow{2}{*}{$\begin{array}{l}\text { Procedure in } \\
\text { ICU }\end{array}$} & No & 8 & $4.25^{*}$ & 1.6 & 5.66 & 1.4 & +24.9 \\
\hline & Yes & 66 & $10.82^{*}$ & 6.4 & 5.63 & 1.9 & -92.2 \\
\hline \multirow{2}{*}{$\begin{array}{l}\text { Surgery During } \\
\text { ICU Stay }\end{array}$} & No & 67 & $9.52^{*}$ & 5.9 & 5.65 & 1.8 & -68.5 \\
\hline & Yes & 7 & $13.86^{*}$ & 7.7 & 5.93 & 1.9 & -133.7 \\
\hline \multirow{4}{*}{$\begin{array}{l}\text { Attending } \\
\text { Physicians }^{\dagger}\end{array}$} & $\mathrm{A}^{\dagger}$ & 7 & 9.57 & 6.1 & 5.94 & 1.4 & -61.1 \\
\hline & $\mathrm{B}^{\dagger}$ & 38 & 8.87 & 5.8 & 5.84 & 1.9 & -51.9 \\
\hline & $\mathrm{C}^{\dagger}$ & 6 & 14.50 & 7.5 & 4.11 & 1.5 & -252.8 \\
\hline & $\mathrm{D}^{\dagger}$ & 24 & 11.17 & 6.9 & 5.59 & 1.8 & -99.8 \\
\hline \multirow{2}{*}{$\begin{array}{l}\text { Mechanical } \\
\text { Ventilation }\end{array}$} & No & 10 & $4.70^{*}$ & 1.7 & 4.37 & 1.4 & -7.6 \\
\hline & Yes & 65 & $10.95^{*}$ & 6.4 & 5.82 & 1.8 & -88.1 \\
\hline \multirow{4}{*}{$\begin{array}{l}\text { Dialysis } \\
\text { Frequency }\end{array}$} & 0 & 40 & 8.80 & 5.9 & 6.05 & 1.8 & -45.5 \\
\hline & 1 & 5 & 7.80 & 4.9 & 5.87 & 1.3 & -32.9 \\
\hline & $2-6$ & 20 & 9.85 & 6.3 & 5.31 & 1.6 & -85.5 \\
\hline & $>6$ & 10 & $17.10^{*}$ & 5.2 & 4.46 & 1.7 & -283.4 \\
\hline \multirow{2}{*}{$\begin{array}{l}\text { Payment } \\
\text { Source }\end{array}$} & Self & 54 & 9.54 & 6.3 & 5.72 & 1.8 & -66.8 \\
\hline & Others & 21 & 11.62 & 6.5 & 5.40 & 1.9 & -115.2 \\
\hline
\end{tabular}

* Statistically significantly different (unpaired/paired $t$-Test/ANOVA from other members of the grouped category).

${ }^{\ddagger}$ Percent difference $=[($ mean Predicted LOS - mean Actual LOS $) /$ mean Predicted LOS $] \times 100$.

${ }^{\dagger}$ Attending physician/physician groups - de-identified data. 
The Pearson's correlation coefficient values for linear association between ICU-LOS with potentially important variables were as follows: number of days on MV $(r=.91)$; APACHEIV score $(r=-0.06)$; age $(r=-0.08)$; and total hospital stay $(r=0.4)$. Therefore a strong correlation was seen between mean ICU-LOS and number of days patients were on MV. The correlation of APACHE-IV score and predicted ICULOS was low $(r=0.26)$.

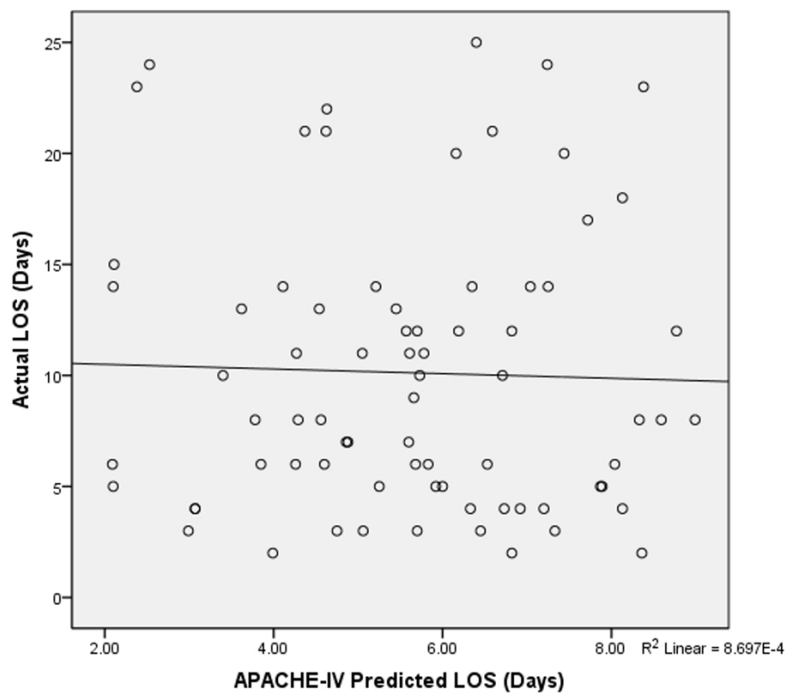

Figure 1. Scatterplot with linear regression line showing association of actual LOS and APACHE-IV predicted LOS among severe sepsis patients. Because the predicted score is registered at admission, and the actual LOS is found later in time, the graph shows Actual LOS on the Ordinate (model $\left.R^{2}=0.001\right)$.

An important difference between actual ICU-LOS and APACHE-IV predicted ICU-LOS was that whereas actual ICU-LOS was statistically significantly greater for those receiving blood transfusion $(p<.001)$; having any procedure in ICU $(p<.001)$; and those with high frequency of dialysis $(p<.001)$, APACHE-IV prediction totally failed to predict ICU-LOS differences in these groups (see Table 2).

\section{Discussion}

Overall, we found that APACHE-IV predicted ICU-LOS for severe sepsis patients very poorly and inconsistently. APACHE-IV prediction was on an average 4.5 days lower than actual ICU-LOS. The key impact of APACHE-IV is predicative on its accurate prediction of ICU-LOS. The authors of the scoring system have clearly stated that APACHEIV benchmarks for ICU stay are useful for assessing the efficiency of unit throughput and support examination of structural, managerial, and patient factors that affect ICU stay. ${ }^{[11]}$ Data from studies in the U.S. suggest that ICU beds

Published by Sciedu Press account for $5 \%$ to $10 \%$ of inpatient hospital beds, while consuming between $20 \%$ and $30 \%$ (or more) of hospital budgets. Critical care usually generates $8 \%$ of healthcare costs and makes up more than $1 \%$ of the gross domestic product. In addition to being the most expensive hospital environment to provide patient care, ICUs are also locations with higher potential for adverse patient events because of the number of invasive lines, tubes, drains, and equipment used to provide care. ${ }^{[14]}$ In a study, Beckmann et al. found that for 176 ICU admissions during a 2-month period, 70 ICU-related unintended event or outcome, which could have, or did reduce the safety margin for the patient, were identified ( $40 \%$ cases) $-84 \%$ of the incidents were preventable. ${ }^{[15]}$

Improving the quality of care in ICUs has been shown to reduce costs. For example, Clemmer et al., ${ }^{[16]}$ on measuring severity of illness, ICU-LOS and hospital-LOS, ICU and hospital mortality rates, total hospital costs as analyzed by their cost center, and measures of improvement in specific areas of care, found that a structured quality improvement program focused on ICU led to improvements in care in relation to: glucose control; antibiotic and sedation use; laboratory, radiology, and blood gas utilization; and adult respiratory distress syndrome survival. Furthermore, the program resulted in a severity-adjusted total hospital cost reduction of $\$ 2,580,981$ (1,991 US dollar value) ( $87 \%$ reduction in costs between 1991 and 1995).

For patients who require admission to ICUs, the average total hospital LOS is significantly longer than those that do not require ICU-stays. Therefore, it becomes imperative for the hospital running the ICU to put policies in place that not only plan and use ICU budgets judiciously, but also maximize the efficiency of ICU utilization to maximize effectiveness and benefits for the monies spent. A key factor determining such policy initiatives is a prediction of average LOS in ICUs for patients. Given that patient ICU-LOS may fluctuate by individuals, such micro-information is not useful for policy making. Overall averages and trends allow enough information to make prudent policies.

Widespread concerns about quality, cost, and efficient utilization of health care resources indicate the need for costeffective methods for outcome evaluation. ${ }^{[17]}$ Such data should permit precise evaluation and comparison of ICU effectiveness and efficiency and result in improved methods of risk prediction and evaluation of medical practices. ${ }^{[18]}$ Neikirk et al. demonstrated the usefulness of administrative data in risk adjustment for ICU-LOS. Their regression technique was able to account for a significant amount of variation with clinically meaningful variables derived from ICD-9 diagnosis and procedure codes and other administrative data 
elements. Application of the model revealed considerable variation in risk adjusted ICU-LOS among hospitals. ${ }^{[17]}$

Can one predict ICU-LOS, and if so, does that prediction have useful value? In 2007, a study from The Netherlands, suggested that patient characteristics can be used to create models that will help in predicting ICU-LOS and will result in more efficient use of ICU beds and fewer cancellations. ${ }^{[19]}$ This planning can be improved by the use of tested and validated models designed to predict average LOS in the ICUs as well as LOS in individual patients.

Although a variety of ICU-LOS prediction tools are available, APACHE-IV is commonly used around the world. APACHEIV was developed in a cohort of ICU patients but not specifically for sepsis/severe sepsis patients. It may thus be possible that that APACHE-IV may not be accurate in predicting ICULOS in this subset of patients.

The APACHE-IV model may provide clinically useful ICULOS predictions for critically ill patient groups. ${ }^{[11]}$ However, we found a wide variation in APACHE-IV predicted LOS in individuals - every individual LOS prediction was highly off target. Even though the system was developed for individual patients, the original authors have now stepped away from suggesting that APACHE LOS predictions be used for individual treatment decisions. ${ }^{[20]}$ Most studies validating the APACHE-IV system have assessed its relation to critical illness patho-physiology as proposed by the original authors. ${ }^{[10,11]}$ The authors, soon stated that predictive models have a "modest" window of applicability, and therefore must be revalidated frequently and sent a call for the need for frequent re-estimation of the models. Earlier, their own major re-estimation of APACHE-III resulted in APACHEIV. ${ }^{[21]}$ They also suggested that even though overall accuracy may be achieved, it is also imperative that predictive models work well within diagnostic and treatment subgroups. A study assessing MV found APACHE-IV could not adequately predict ICU-LOS for these patients and suggested that benchmarking measures must consider the case mix of patients receiving different types of $\mathrm{MV},{ }^{[22]}$ an observation similar to ours.

Our study was limited by small sample size that did not permit strong multi-variable analyses. Such analyses could have helped resolve the impacts of different critical conditions identified in Table 2 to determine independent determinants of ICU-LOS and clarified the magnitude of independent predictability of APACHE-IV. Another possible limitation is the lack of strong electronic database. We entered data into an electronic system from paper charts. If the original charts had errors, as many hospital charts do, then those errors were transferred to our dataset as well. Furthermore, this was a hospital-based study and may not represent severe sepsis patient profile in all hospitals. However, this is also an important aspect - because the study demonstrates that in different hospital units, the ICU-LOS prediction by APACHE-IV may not work unlike the prevalent notion. Despite these limitations, the current study has demonstrated that for one of these critical sub-groups (severe sepsis), APACHE-IV predicted ICU-LOS is off-mark consistently (see Table 2). These results also rhyme with the findings of Zilliberg's study of APACHE-IV and MV. ${ }^{[22]}$

In conducting the study, we followed the suggestions by Breslow and Badawi ${ }^{[23]}$ that for assessing ICU-LOS, the ratio of actual-to-predicted outcomes in the study cohort. Our results suggest that the ability of APACHE-IV system to predict ICU-LOS for severe sepsis patients is poor - which has several characteristics. First, the predicted ICU-LOS is off-target by a large margin (average of 4.5 days) which is a substantial for critical patients. Second, the prediction error is not in the same direction (i.e. under/over prediction). If there was a consistent directionality to ICU-LOS prediction (i.e. differential prediction error), then it would be possible to deduce a correction factor for the error to obtain a reliable prediction. Third, the regression line is close to the mean line for actual ICU-LOS (see Figure 2). Therefore, for most of the ICU-LOS distribution, the predicted values (5.6 days +1.78 ) remain far from the observed or the overall-mean ICU-LOS values $(10.1$ days +6.4$)$.

Wang et al. ${ }^{[24]}$ suggested that outcomes for critically ill patients may be influenced by deficiencies in the delivery of care beginning with pre-hospitalization emergency services. Also, the critical illness itself impacts patient outcomes which may occur long after being discharged from the ICU. ${ }^{[25]}$ Furthermore, ICU outcome prediction models is compromised by the lack of standardized data collection and laboratory testing. ${ }^{[26]}$

Lack of inpatient bed availability is a major contributor to emergency department (ED) crowding. ${ }^{[27]}$ Important reductions in LOS at ED (and others) and smoothening of ambulance diversion occur in urban academic medical center after an increase in adult ICU beds. A recent study demonstrated that the most notable change after ICU expansion was a decrease in time spent on ambulance diversion. Increasing ICU beds appears to have shortened ED LOS for ICU patients but has less effect on other admitted patients and apparently no effect on patients discharged home. ${ }^{[27]}$ In emergency care a perfect balance between given resources and demand is much more difficult to achieve and maintain. In reality, certain key resources, e.g. ICU beds, are often over-utilized. ${ }^{[28]}$ Improper estimation of LOS may lead to poor bed-strength 
of ICUs. Therefore, use of a good prediction model for ICULOS can have major implications and efforts should be made to improve ICU-LOS by developing other good tools.

In 2006, Afessa ${ }^{[29]}$ asked if the APACHE-IV can be used for benchmarking in all ICUs. He answered the question saying "I believe we are not there yet". It was suggested that because the APACHE-IV benchmark study was conducted only in the U.S. (104 ICUs of 45 hospitals in the U.S.), the predictive model may not be applicable elsewhere. Even for the U.S., the performance of the APACHE-IV prediction model needs to be validated extensively and generalizability of its results be assessed before endorsing its use elsewhere in the country. The status has not changed much since 2006. Therefore, because of its wide-spread uses in several international settings, it is time to validate APACHE-IV prediction in a variety of settings. Furthermore, it has been suggested that not just
APACHE-IV, but all scoring systems for the critically ill will need updating because ICU populations change with time and new diagnostic, therapeutic and prognostic techniques become available. ${ }^{[30]}$

\section{Conclunsions}

This study provides indication that overall, APACHE-IV poorly predicted ICU-LOS in severe sepsis cases. Overall, the under-prediction of actual ICU-LOS was by about 4.5 days. This underestimation is about $44.5 \%$ of the actual mean ICU-LOS and dependence on this prediction method may adversely impact hospital readiness for accommodating and managing patients in ICUs. Correct prediction of LOS in ICUs impacts clinical as well financial outcomes of the ICUs and the hospital because ICUs are considered major revenue generators for hospitals.

\section{REFERENCES}

[1] American College of Chest Physicians/Society of Critical Care Medicine Consensus Conference: Definitions for sepsis and organ failure and guidelines for the use of innovative therapies in sepsis. Crit Care Med. 1992; 20: 864-74. PMid:1597042. http: //dx.doi.org/10.1097/00003246-199206000-00025

[2] Sands KE, Bates DW, Lanken PN, et al. Epidemiology of sepsis syndrome in eight academic medical centers. JAMA. 1997; 279: 234-40.

[3] Anderson RN, Smith BL. Deaths: Leading causes for 2001. National Vital Statistics Reports. 2003; 52: 1-86.

[4] Linde-Zwirble WT, Angus DC. Severe sepsis epidemiology: sampling, selection, and society. Critical Care. 2004; 8: 222-6. PMid:15312201.

[5] Bone RC, Balk RA, Cerra FB, et al. Definitions for sepsis and organ failure and guidelines for the use of innovative therapies in sepsis. The ACCP/SCCM Consensus Conference Committee. American College of Chest Physicians/Society of Critical Care Medicine. Chest. 1992; 101: 1644-55.

[6] Angus DC, Linde-Zwirble WT, Lidicker J, et al. Epidemiology of severe sepsis in the United States: Analysis of incidence, outcome, and associated costs of care. Crit Care Med. 2001; 29: 1303-10. PMid:11445675. http://dx.doi.org/10.1097/00003246-200 107000-00002

[7] Ponce de Leon-Rosales SP, Molinar-Ramos F, Dominguez-Cherit G, et al. Prevalence of infections in intensive care units in Mexico: a multicenter study. Crit Care Med. 2000; 28: 1316-21. PMid:10834672.

[8] Chatterjee S. Epidemiology of severe sepsis in the intensive care unit of a tertiary care hospital in Kolkata. Dissertation submitted to The National Board of Examinations, New Delhi, in partial fulfillment towards the requirements for the degree of Diplomate National Board in Family Medicine; 2009.

[9] Open Clinical. Quality assurance and administration systems, decision support systems. Available from: http://www. openclinic al.org/aisp_apache.html. Accessed August 21, 2012.

[10] Zimmerman JE, Kramer AA, McNair DS, et al. Acute Physiology and Chronic Health Evaluation (APACHE) IV: hospital mortality assessment for today's critically ill patients. Crit Care Med. 2006; 34: 1297-310. PMid:16540951. http://dx.doi.org/10.1097/0 1. CCM. 0000215112.84523 .FO

[11] Zimmerman JE, Kramer AA, McNair DS, et al. Intensive care unit length of stay: Benchmarking based on Acute Physiology and Chronic Health Evaluation (APACHE) IV. Crit Care Med. 2006; 34: 2517-29. PMid:16932234. http://dx.doi.org/10.1097/01.CC M. 0000240233.01711.D9

[12] Cowboy E, Simmons R, Nygaard S. APACHE-IV a valuable data tool. Available from: http://www.americantelemed.org/files/ public/MemberGroups/TeleICU/APACHE\%20IV.pdf Accessed August 21, 2012

[13] Yamin S, Vaswani AK, Afreedi M. Predictive efficasy of APACHEIV at ICU.S of CHK. Pak J Chest Med. 2011; 17: 1-14.

[14] Hampton D, Norton J. A Model for quantifying quality initiatives in intensive care. J Nurs Care Qual. 2006; 21: 70-7. http: //dx.doi.org/10.1097/00001786-200601000-00014

[15] Beckmann U, Bohringer C, Carless R, et al. Evaluation of two methods for quality improvement in intensive care: facilitated incident monitoring and retrospective chart review. Crit Care Med. 2003; 31: 1-19.

[16] Clemmer TP, Spuhler VJ, Oniki TA, et al. Results of a collaborative quality improvement program on outcomes and costs in a tertiary critical care unit. Crit Care Med. 1999; 27: 1-21. PMid:9934869.

[17] Neikirk H, Behal R, Lu L. Development of a risk adjustment methodology for ICU length of stay using administrative data. Academy Health Meet. 2005; 22: abstract no. 4210.

[18] Knaus WA, Wagner DP, Zimmerman JE, et al. Variations in mortality and length of stay in intensive care units. Ann Intern Med. 1993; 118: 753-61.

[19] Van Houdenhoven M, Nguyen DT, Eijkemans MJ, et al. Optimizing intensive care capacity using individual length-of-stay prediction models. Crit Care. 2007; 11: R42. http://dx. doi .org/10.7326 /0003-4819-118-10-199305150-00001

[20] Sirio CA. Critical care performance measurement: the time has come for all. Crit Care Med. 2006; 34: 1538-9. PMid:16633247. http: //dx.doi.org/10.1097/01.CCM.0000216184.53553.DC 
[21] Zimmerman JE, Kramer AA. Outcome prediction in critical care: the Acute Physiology and Chronic Health Evaluation models. Curr Opin Crit Care. 2008; 14: 491-7. PMid:18787439. http://dx.doi.org /10.1097/MCC.0b013e32830864c0

[22] Zilberberg MD, Kramer AA, Higgins TL, et al. Prolonged acute mechanical ventilation: implications for hospital benchmarking. Chest. 2009; 135: 1157-62. PMid:19118268. http://dx.doi.org/10. 1378/chest .08-1928

[23] Breslow MJ, Badawi O. Severity scoring in the critically ill: part 1-interpretation and accuracy of outcome prediction scoring systems. Chest. 2012; 141: 245-52. PMid:22215834. http://dx.doi.org /10.1378/chest.11-0330

[24] Wang HE, Lave JR, Sirio CA, et al. Paramedic intubation errors: isolated events or symptoms of larger problems? Health Aff (Millwood). 2006; 25: 501-9. PMid:16522604. http://dx.doi.org/10.1377 /hlthaff.25.2.501

[25] Angus DC, Musthafa AA, Clermont G, et al. Quality-adjusted survival in the first year after the acute respiratory distress syndrome.
Am J Respir Crit Care Med. 2001; 163: 1389-94

[26] Afessa B, Keegan MT, Gajic O, et al. The impact of missing components of the acute physiology score on the standardized mortality ratio calculated by the APACHE III prognostic model. Crit Care. 2005; 9: S96-7.

[27] McConnell KJ, Richards CF, Daya M, et al. Effect of increased ICU capacity on emergency department length of stay and ambulance diversion. Ann Emerg Med. 2005; 45: 471-8. PMid:15855939. http: //dx.doi.org/10.1016/j.annemergmed.2004.10.032

[28] Örtenwall P, Hedelin AHE, Wahl M, et al. Surge capacity in a costeffective healthcare system. ICU Management. 2009; 3: 34-5.

[29] Afessa B. Benchmark for intensive care unit length of stay: One step forward, several more to go. Crit Care Med. 2006 Oct; 34: 2674-6. PMid:16983264. http://dx.doi.org/10.1097/01.CC M.0000240232.65217.83

[30] Vincent JL, Moreno R. Clinical review: scoring systems in the critically ill. Crit Care. 2010; 14: 207. PMid:20392287. http: //dx.doi.org/10.1186/cc8204 